\title{
Access to care in advanced COPD: factors that influence contact with general practice services
}

\author{
*Cathy Shipman, ${ }^{\mathrm{a}, \mathrm{b}}$ Suzanne White, ${ }^{\mathrm{a}}$ Marjolein Gysels, ${ }^{\mathrm{b}}$ Patrick White \\ a Department of General Practice and Primary Care, King's College London, London, UK \\ ${ }^{b}$ Department of Palliative Care, Policy and Rehabilitation, King's College London, London, UK
}

Received 27th June 2008; revised version received 3rd October 2008; accepted 22nd December 2008; online 31st March 2009

\begin{abstract}
Aims: To explore factors that influence the use of general practice services by people with advanced COPD.

Method: An exploratory qualitative study using in-depth interviews at home with 16 patients who had advanced COPD, recruited through general practices in south-east London. The Framework Approach was used to analyse interview transcripts.

Results: Interviewees had a mean age of 70 and a mean $\mathrm{FEV}_{1}$ of $24 \%$ predicted. All reported severe breathlessness. They contacted general practices for routine, urgent and emergency care. Contact was influenced by perceptions of ease of access, quality of relationship with their general practitioner (GP), and perceived disease severity and threat. Some patients wanted to avoid bothering the doctor or found travelling to the surgery too difficult.

Conclusion: Factors other than need influenced patterns of health service use. Expectations of difficulty in access, and poor relationships with their GP, may have delayed help-seeking in severe acute exacerbations.

(C) 2009 General Practice Airways Group. All rights reserved.

C Shipman et al. Prim Care Resp J 2009; 18(4): 273-278.

doi:10.4104/pcrj.2009.00013
\end{abstract}

Keywords COPD, end of life care, palliative care, access, service use, general practice, primary medical care

\section{Introduction}

A palliative care approach in advanced chronic obstructive pulmonary disease (COPD) has recently become a recognisable theme within the literature, ${ }^{1-12}$ with increasing recognition of the need for symptom control. Good access to general practice may enable access to primary palliative care and referral to specialist services, even when prognosis is uncertain. However, little is known from the patient's perspective about service use and help-seeking when suffering from severe disease.

Patients with advanced COPD can suffer severe symptoms (breathlessness, cough, depression, pain, fatigue, loss of appetite) together with isolation and loneliness which increasingly constrains their quality of life. ${ }^{4,8-10}$ They have a high symptom load in the last year of life and patients dying from COPD are reported to receive inadequate services and surveillance. ${ }^{4}$ More than a third saw their general practitioner (GP) at less than three-monthly intervals or not at all, and almost half did not receive regular checkups for their COPD either at hospital or by their GP. Patients with severe COPD are likely to have less access to generalist or specialist supportive and palliative care than those suffering from lung cancer, despite comparable symptom severity and death rates. ${ }^{9,12,13}$

The disabling impact of severe symptoms has been shown to affect help-seeking. ${ }^{14}$ The surreptitious onset of breathlessness can lead to the 'invisibility' of COPD, with associated problems in management and stigma. ${ }^{15}$ Many patients suffering from chronic disease develop expertise in their condition, but loss of self esteem and hope, and increased fear about the future, limit help-seeking and foster inappropriate concerns about being a 'good patient'. 10,15 COPD patients can fear abandonment by physicians at the end of life and have limited opportunity to discuss end-of-life care in comparison to patients suffering from diseases such as cancer. ${ }^{13}$ Difficulties in making prognoses for such patients

\footnotetext{
* Corresponding author: Ms Cathy Shipman, General Practice \& Primary Care, King's College London, 5 Lambeth Walk, London, SE11 6SP, UK. Tel: +44 (0)207848 5567 Fax: +44 (0)2078485517 E-mail: catherine.shipman@kcl.ac.uk
} 
can be a contributory factor. Many patients will die in hospital following admission for an acute exacerbation. ${ }^{17,18}$

We conducted a qualitative study to explore service use as part of a study of palliative care needs in patients with advanced COPD. In this paper we report on the reasons for variation in contact with general practitioner services.

\section{Method}

This was a prospective qualitative interview study on patients with advanced COPD in an inner city area. We recruited patients from six general practices (list sizes 6000 - 18,500 patients) and a district general hospital in an inner city area. All practices served a population of mixed socio-economic and ethnic groups.

Inclusion criteria included at least two of the following identified from patient records: a forced expiratory volume in one second $\left(\mathrm{FEV}_{1}\right) \leq 30 \%$ predicted; long term oxygen therapy; more than one acute exacerbation in the previous year; breathlessness on most days; being housebound; and the presence of cor pulmonale. We did not exclude those suffering other co-morbidities where COPD presented the main symptom burden, although we did exclude those suffering from lung cancer. Letters were sent by the practice or hospital clinic to the patients, together with an information sheet and invitation to undertake an interview. The letter was followed-up by a telephone call where the patient's telephone number was available. Informed consent was obtained before the interviews, all of which took place in the patients homes.

A topic guide was developed drawing on question areas from an earlier retrospective survey ${ }^{4}$ and a literature search. The guide was extended as interviews progressed to incorporate additional topics of importance to participants. It included open questions to explore patient experience of symptoms, the impact of the illness, perceptions of availability and use of health services (the GP and other practice staff), communication with health care professionals, and perceived need for current and future care. A spirometry test was undertaken at the beginning of the interview and the patient's score on the MRC dyspnoea scale was recorded. ${ }^{20}$ Socio-demographic data were also collected. The interviews took between 30 and 80 minutes to complete and were all conducted by CS. Here we report on responses concerning GP service use. Although patients invariably referred to the service as "the GP" or "the GP's practice (or surgery)", we asked specifically about access to other members of the practice or primary care team.

Interviews were tape-recorded and transcribed with the individuals' permission. The Framework Approach ${ }^{21}$ was used to explore, compare and contrast key themes arising from the interview data. A coding framework was generated using NVivo $7^{22}$ and this was then used to code all transcripts and to compare and contrast themes between interviews. Analysis was undertaken by CS in discussion with PW, SW and MG. The study received approval from King's College Research Ethics Committee.

\section{Results}

\section{Responses}

Forty-two patients with severe COPD were invited to take part, but 22 patients did not participate: nine did not reply to the invitation and had no telephone number for contact; six did not respond to telephone follow-up; two died before the interview could be arranged; two postponed interviews because they felt too ill; one refused; one was better than indicated from the medical record; and one patient was admitted to hospital. Twenty interviews were therefore undertaken.

Of the 20 patients interviewed, four were excluded from the analysis because at interview they had an $\mathrm{FEV}_{1}>30 \%$ predicted, not reported in practice records. Four other patients had an $\mathrm{FEV}_{1}>30 \%$ predicted but qualified for inclusion because of the severity of their reported breathlessness. ${ }^{23,24}$ We did not obtain spirometry results for three individuals because of the severity of their illness or refusal at interview; nevertheless, all three were included in the analysis because they were breathless at rest or on limited exertion, had suffered acute exacerbations, and/or were receiving long term oxygen therapy. Sixteen patients were therefore eligible for the study.

\section{Characteristics of patients}

The characteristics of the 16 eligible interviewees are given in Table 1. All interviewees reported suffering from breathlessness on most days or everyday, 14 reported cough on most days or everyday, 11 reported pain on most days or everyday, and 10 reported tiredness most days or everyday. Other symptoms reported included weight loss, low mood and anxiety. Ten interviewees reported having co-morbidities including heart disease, rheumatoid arthritis, diverticulitis, osteoporosis and diabetes mellitus.

\section{Reasons for making contact with general practices}

Interviewees reported contact with their general practices in three categories of need: routine, urgent and emergency. Routine contact was necessary for getting repeat prescriptions, for regular appointments to monitor progress or undertake tests, and for drug treatment and referral to other services (see Table 2). Urgent contact was required for worsening symptoms due either to COPD or to other conditions. Emergency contact was needed for acute exacerbations of COPD or acute onset of other conditions (see Table 3).

Contact with practices was often made by family and neighbours on behalf of the interviewee but this depended on 


\begin{tabular}{|c|c|}
\hline Interviewee characteristics & $n=16$ \\
\hline Male & $9(56 \%)$ \\
\hline Mean age & 70 (range 54-86) \\
\hline Had a carer & $14(70 \%)$ \\
\hline Living alone & $6(30 \%)$ \\
\hline Oxygen at home & $10(50 \%)$ \\
\hline Acute exacerbations in last year & $11(55 \%)$ \\
\hline Mean $\%$ predicted FEV 1 & $24 \%$ (range $15-39 \%)^{*}$ \\
\hline MRC dyspnoea scale grade & $\begin{array}{l}\text { MRC3 = } 2 \\
\text { (Walks slower than contemporaries on } \\
\text { the level because of breathlessness, or } \\
\text { has to stop for breath when walking } \\
\text { on the level). } \\
\text { MRC4 }=7 \\
\text { (Stops for breath after about } 100 \mathrm{~m} \text { or } \\
\text { after a few minutes on the level) } \\
\text { MRC } 5=7 \\
\text { (Too breathless to leave the house or } \\
\text { breathless when dressing or } \\
\text { undressing) }\end{array}$ \\
\hline
\end{tabular}

${ }^{\star} \mathrm{FEV}_{1}$ of 3 patients was over $30 \%$ predicted $-31 \%, 34 \%, 39 \%$

their proximity and perceived helpfulness. Interviewees living with family members frequently reported help-seeking undertaken by their relatives on their behalf. Those living alone were often housebound and dependent on the goodwill of neighbours who might be their first port of call either for direct help or to contact a family member.

\section{Routine contact with the general practice}

The general practice was a potential source of routine support for all interviewees, and ten described the good relationships that they had with a doctor at the practice (Table 2). These included having easy access, confidence that the doctor would take their concerns seriously, perception of the willingness of the doctor to visit when necessary, and perceptions of the doctor's awareness of the extent of their problems. Continuity of care was important to establish trust. Some said that while they saw whichever doctor was currently on duty, they came to know one or two GPs who were more familiar with their illness.

Interviewees reported varying personal contact with the practice - ranging from every 4-5 weeks or when needed, to no contact in 3-4 years. All patients reported some routine contact with the practice which, for some, included monitoring of spirometry tests by practice or respiratory nurses. Contact with practices for repeat prescriptions seldom led to face-to-face consultations.

Telephone contact enabled some interviewees to develop
Table 2. Making routine contact with the GP practice: interviewee experiences.

"Our GP is very good really and all the staff, you know the nursing staff are all so nice ... and the girls on the desk ...and I mean when I phone up for a prescription or anything the girls answering the phone are so goodare you sure there's nothing else you want ... and you know they just send it around for the (pharmacist)" (Interviewee 12, 70 year old woman living with disabled husband)

"But if I need to see him in-between I just phone up and they'll give me an appointment ... I've seen him for years now so he knows if I'm not well, he says 'sit down there you're not well today' ... 'It's a bad day', or it's 'you look good today' ... Yeah I can talk to him if I don't like the tablet he's given me I tell him, 'I don't want that one, don't give me that one again,' " (Interviewee 15, 60 year old woman living with family)

"Yes, she (GP) keeps in contact every so often and then, she will come and see me now, she is not too bad and I can call her anytime I want to, and usually when I get to her about things, she does it right away, she is good that way." (Interviewee 9, 62 year old man living alone)

good relationships, but knowing that the GP would be willing to visit was important for reassurance.

\section{Urgent and emergency contact}

Urgent contact with general practices was generally made to ask for help with the onset of worsening symptoms when the interviewee had developed a chest infection or a cold (see Table 3). Emergency contact was reported when the interviewee felt they could no longer cope with an acute exacerbation of COPD. Urgent and emergency contact was reported with the GP rather than with other practice staff.

There were different patient pathways to help-seeking during severe acute exacerbations. For some, contact was made with the GP or through a primary care out-of-hours

Table 3. Making urgent and emergency contact with the GP practice: interviewee experiences.

"... I didn't feel very well, went to bed ... couldn't breathe, couldn't get my breath and needed to go to the loo desperately so I got out, it was early in the morning about five o'clock. And I went outside (in the hall), crawled to the toilet ... and the pains in my side were horrific. I was on my own and just lay there really at the top of the stairs and my son came in about eight o'clock and that same time I was calling the doctor for advice, what to do and the doctor told him just to get me into hospital and get to the ambulance to take me to hospital and the ambulance come and took me." (Interviewee 13, 67 year old woman living alone)

"I was alright in the morning, and by the lunchtime I was feeling sick and I kept getting this sharp pain, I couldn't even walk up the stairs in the end and that's when I went up the doctors and I told him you know ... I couldn't breathe because of the pain." (Interviewee 1, 77 year old man living with his wife)

"There was not, (coughing) there was not enough air going in my lungs, so I couldn't breathe ... nothing was helping ... (it was) not clearing and I had enough, and I went to the doctor, and when I went ...I didn't even leave the surgery he just called the ambulance, and I went straight into hospital" (Interviewee 10, 54 year old woman living alone) 
organisation. One interviewee described phoning her GP when she thought her symptoms were worse than usual and then being told to call an ambulance.

Some patients who were concerned not to bother the GP unnecessarily actually visited the practice even when they were in severe difficulty. Two interviewees reported that the GP had phoned up for an ambulance immediately on their arrival which had then transported them to hospital.

For some, the onset of acute breathlessness was so intolerable that there appeared to be no other option than an acute hospital admission. Other interviewees who had frequent inpatient admissions reported forming good relationships with the consultant and members of the clinical team.

\section{Barriers to contacting the practice}

Six interviewees described barriers to access to routine appointments and to their proactive contact with the practice (Table 4). Feeling that there was little the doctor could do, not wanting to bother the doctor, and not wanting to know too much about the illness, were all reported as barriers to initiating contact. An elderly woman who lived alone wore a helpline disc and used this to call for help as she said she never saw her GPs and so didn't think of contacting them.

Difficulties in accessing the practice were also cited as

Table 4. Barriers to making contact with the GP practice.

Not wanting to bother the doctor

"I try to go down and get my prescription because some people are at their doctors if they've got a cold or even if the wind blows the wrong way. I try not to bother them ..." (Interviewee 11, 60 year old man living with wife)

Travelling to the practice in pain

"My last experience of going to the doctors... I phoned up and he said well come down. Oh and the pain that I felt walking into the, waiting, getting there and waiting .... I found it quite heartless really. That he, you know, expecting me to go all the way down there (Interviewee 13, 67 year old woman living alone)"

Not knowing when it is appropriate to call for help

"... I'm virtually house bound ... and I don't like to call a doctor out and you know always have a problem with (home visits) coz I never feel as though I'm ill enough to ask them to come out to see me, you know what I mean? (Interviewer: Even when you're feeling very poorly?) Even when I'm feeling ... if I'm that poorly I'm usually on the way to the hospital the last time I called the doctor was I was actually on ... (when you get depressed about things you tend to ... get on with it you know)..

I was on my way to the hospital at the same time" (Interviewee 16, 80 year old man living alone)

\section{Lack of continuity of care}

that's been a bit of a problem because the doctor you had last year, do you remember (Dr. X) coz she'd been on maternity leave ... And he's not had a regular doctor since then ....and getting regular doctors at the GP practices and when he's been in hospital is a very big issue ... You know there's not been kind of anybody overseeing the whole thing really" (Interviewee 10, wife of 74 year old man who participated in the interview) reasons for lack of contact; these included problems in arranging transport, the strain of walking the distance from the car park to the surgery, and the strain of climbing stairs to reach the consultation room. Experience and expectation of slow responses to telephone requests for medication were reported as barriers to proactive contact, and one interviewee described a 4-5 day delay after making an urgent request for medication. Anticipating a practice answerphone was also cited as a barrier.

The frequency with which patients had received home visits varied from one or two visits within the previous six months to a home visit two years previously. Home visits were infrequent events for most patients, and difficulty in knowing when it was appropriate to phone and ask for help could be particularly problematic for the housebound. Lack of continuity of care could also be a problem when it was unclear who was providing overall care.

Three interviewees talked about phoning directly for an ambulance when symptoms were worsening - one because he assumed the GP would not visit before five o'clock in the evening, another because he was out of his home neighbourhood and visiting a relative, and a third because of the fear of breathing problems and pain. A further interviewee had formed a good relationship with the ambulance service which she contacted in preference to her GP.

\section{Discussion}

We report new findings about factors that affect the way GP services were used. Interviewee expectations of support and perceptions of ease of access as well as urgency of need reflected patterns of contact with their GP. The GP, rather than other practice staff, was often the first line of support for routine and urgent care (and for some, emergency care) in terms of referral to hospital during acute exacerbations following a home visit, a telephone consultation, or a visit to the practice. Where interviewees reported regular routine appointments or proactive contact with their practice for worsening symptoms, this was often accompanied by expressions of confidence in the accessibility of the practice. Feeling that the GP was approachable and would take their concerns seriously reassured interviewees about help being available when needed and motivated them to make contact for urgent help when symptoms were worsening. Continuity of care by one or more doctors who knew the patient's condition was also found to be important, with lack of continuity being associated with poor overall management of care.

Some interviewees did not report routine face-to-face or verbal contact with their GP and sometimes did not make contact for worsening symptoms. This corresponds with Elkington et al's findings that about a third of individuals had 
GP contact only every three months in the last year of life and about a third had contact less than three-monthly or not at all. ${ }^{4}$ Feeling that there was little a GP could do, and not wanting to bother the doctor 'inappropriately', may have postponed help-seeking that might have averted an acute admission to hospital. These new findings are in keeping with the views reported in an earlier study by bereaved carers that their relatives who had died from COPD had often received inadequate services and surveillance. ${ }^{4}$ Concerns about the limitations of help that could be offered, or about offending the doctor by making unnecessary contact, may have reflected a limited or unsatisfactory relationship between patient and practitioner amongst some individuals in this group with severe COPD. Loss of self esteem resulting from their worsening condition ${ }^{15}$ may contribute to difficulties some people have in thinking that their need for help is valid. There may be need for more frequent structured reviews with patients who are seldom in contact with their GP.

Acute exacerbations are the major cause of death in advanced COPD, and exacerbations are more severe and more frequent in those with severe disease. ${ }^{17,18}$ A number of interventions can reduce the frequency and severity of COPD exacerbations, including treatment with inhaled steroids, long-acting inhaled bronchodilators, and pulmonary rehabilitation. For these reasons, easy and responsive access to clinical care is important in advanced COPD so that treatment can be optimised and effective and early interventions can be made. In some of these patients the possible unsuitability of admission in a future exacerbation, and alternatives such as a palliative care approach, are clinical issues that need to be considered together with referral to specialist palliative care professionals. Gysels has found that anxiety about confronting the future may be a barrier to helpseeking $^{15}$ and Curtis has found that patients with severe COPD have little opportunity for discussions about end-of-life issues. ${ }^{25}$ While this may reflect a reluctance on the part of patient as well as clinician, it may also limit help-seeking behaviour. The role of continuity, either personal continuity or organisational continuity, may also be important for patients with severe COPD as regards their use of services in both routine and urgent circumstances and in an emergency. Further research is needed in this area; there is good evidence for the impact of continuity of care on patients' satisfaction, but its role in the outcome of disease is less clear. ${ }^{26,27}$

While most respondents had received a home visit, there was a lack of clarity for some over when this was appropriate. A few interviewees reported travelling to the general practice while suffering from an acute severe exacerbation that was so severe that it led to them being sent on to hospital immediately. This suggests a need for more investigation of the role of patient education and patient self-management plans in patients with severe disease. Some with severe comorbidities reported easy access to home visits. Elkington et al's study, however, suggests that some of those with least mobility were reported to have less GP contact than those more able to get to the practice. ${ }^{4}$ They reported a decline in GP contact over time in comparison to previous study findings, ${ }^{12}$ possibly related to a decline in home visiting. ${ }^{4}$

There were practical obstacles to making contact for some interviewees relating to travelling to the practice. A few patients with severe breathlessness reported difficulty in walking the distance from the car park to the practice building, and once inside had difficulty in walking to the doctor's consulting room especially if it was upstairs. Ensuring easier access to the GP or practice nurse might foster more proactive use of the practice.

Telephone contact is a means by which patients are able to gain support from the practice, and differing experiences and expectations were reported by interviewees. Our results suggest that good relationships with practice staff encouraged help-seeking, but expectations of answerphone messages and delays in returning urgent calls could be a barrier Some practices make special arrangements for responding to palliative care patients, for example those working within the Gold Standards Framework. ${ }^{28}$ It is likely that such arrangements are available more commonly for patients suffering from cancer rather than COPD. Reviewing arrangements for the management of advanced COPD may enable the establishment of more responsive general practice services for this vulnerable group and greater involvement of other practice staff.

Little is known about primary care service use by patients with advanced COPD, and this qualitative study adds to the knowledge base. Although this was a small study, our new findings on patterns of help-seeking and the reasons given for the way help was sought reveal important barriers to effective primary care of patients with advanced COPD. We cannot know how representative such patterns are of the general population of patients with advanced COPD, of service use in different sizes of practices, or of service use in other geographical areas. We also do not know the extent to which non-responders follow the patterns of help-seeking that we have identified, and whether different patterns would be reported by those who were too ill to undertake an interview. Recruiting patients with severe disease is challenging. Difficulties in responding to a letter of invitation for the housebound may contribute to non-response rates. An 'opt out' approach whereby the research team make contact to ensure the patient has received information about the study and clarify reasons for non-response may improve participation.

In conclusion, patients with advanced COPD are likely to 
be influenced in the way they seek help by factors such as ease of access, perceptions of appropriateness, anticipation of a supportive therapeutic relationship, and not wanting to bother the doctor. When in need for help, patients reported contacting the GP rather than other practice staff. Those enjoying better relationships with practitioners and anticipating easier access to the practice during routine contact may be more likely to seek help when symptoms worsen and to avoid the hospital admissions that can follow acute exacerbations.

It is difficult to predict how close people with severe COPD are to the end of their lives. Such people often live in isolation, coping with severe and distressing symptoms. For those with severe COPD who do not make routine contact, proactive contact by the GP or other practice member might be helpful. For those with limited contact with primary care services alternative approaches might be needed to improve their access to care during acute exacerbations of the disease. These might include outreach respiratory nurses based in a local hospital, rapid response teams, a telephone helpline, or case management approaches.

\section{Acknowledgements}

We are grateful to the patients who participated in the interviews and to the practices that provided support in terms of recruitment.

\section{Funding body and reference number}

Guy's and St. Thomas Charity ref RO41038

\section{Ethics committee and reference number}

King's College Hospital NHS Foundation Trust REC number 05/Q0703/91

\section{Conflicts of interest}

None

\section{References}

1. Rocker GM, Sinuff T, Horton R, Hernandez P. Advanced chronic obstructive pulmonary disease: innovative approaches to palliation. I Palliat Med 2007;10(3):783-97. doi:10.1089/jpm.2007.9951

2. Seamark DA, Seamark CJ, Halpin MG. Palliative care in chronic obstructive pulmonary disease: a review for clinicans. I $R$ Soc Med 2007;100:225-33. doi:10.1258/jrsm.100.5.225

3. Curtis JR. Palliative care and end-of-life care for patients with severe COPD. Eur Respir J 2008;32(3):796-803. Epub 2007 Nov 7. doi:10.1183/09031936. 00126107

4. Elkington $H$, White P, Addington-Hall J, Higgs R, Edmonds P. The healthcare needs of COPD patients in the last year of life. Palliat Med 2005;19:485-91. doi:10.1191/0269216305pm1056oa

5. Knauft, E, Neilson EL, Engelberg RA, Patrick DL, Curtis JR. Barriers and facilitators to end of life care communication for patients with COPD. Chest 2005;127:2188-96. doi:10.1378/chest.127.6.2188

6. Mulcahy, P, Buetow S, Osman L, Coster G, Bray Y, White P, Elkington H. GPs' attitudes to discussing prognosis in severe COPD: an Auckland (NZ) to London (UK) comparison. Family Practice 2005;22:538-40. doi:10.1093/ fampra/cmi052

7. Murray, S, Pinnock $H$, and Sheikh A. Palliative care for people with COPD: we need to meet the challenge. Prim Care Resp J 2006;15(6):362-64. doi:10.1016/j.pcrj.2006.08.008

8. Varkey, B. Unfulfilled palliative care needs of chronic obstructive pulmonary disease patients. Curr Opin Pulm Med 2006;12:103-05. doi:10.1097/ 01. mcp.0000208448.65478.8f

9. Gore JM, Brophy CJ, Greenstone MA. How well do we care for patients with end stage chronic obstructive pulmonary disease (COPD). A comparison of palliative care and quality of life in COPD and lung cancer. Thorax 2000; 55:1000-06. doi:10.1136/thorax.55.12.1000

10. Goodridge D. People with chronic obstructive pulmonary disease at the end of life: A review of the literature. Int J Palliat Nurs 2006;12(8):390-6.

11. World Health Organisation. National cancer control programmes: policies and managerial gudielines, 2nd ed. World Health Organization, Geneva, 2002.

12. Edmonds, $\mathrm{P}$, Karlson $\mathrm{S}$, Khan $\mathrm{S}$, Addington-Hall J. A comparison of the palliative care needs of patients dying from chronic respiratory diseases and lung cancer. Palliat Med 2001;15:287-95. doi:10.1191/026921601 678320278

13. Curtis JR, Wenrich MD, Carline JD, Shannon SE, Ambrozy DM, Ramsey PG. Patients' perspectives on physician skill in end-of-life care: differences between patients with COPD, Cancer and AIDS. Chest 2002;122:356-62. doi:10.1378/chest.122.1.356

14. Oliver S. Living with failing lungs: the doctor patient relationship. Family Practice 2001;18(4):430-9. doi:10.1093/fampra/18.4.430

15. Gysels M, Higginson IJ. Access to services for patients with chronic obstructive pulmonary disease: the invisibility of breathlessness. J Pain Symptom Manage 2008;36(5):451-60. Epub 2008 May 20. doi:10.1016/ j.jpainsymman.2007.11.008

16. Adams R, Chavannes N, Jones K, Ostergaard MS, Price D. Exacerbations of chronic obstructive pulmonary disease - A patients' perspective. Prim Care Resp J 2006;15(2):102-09. doi:10.1016/j.pcrj.2006.01.003

17. Burge S, Wedzicha WA. COPD exacerbations: definitions and classifications Eur Resp J 2003;21:46S-53S.

18. Wedzicha AJ, Seemungal TAR. COPD exacerbations: defining their cause and prevention. The Lancet 2007;370:786-96. doi:10.1016/S01406736(07)61382-8

19. Wilkinson TMA, Donaldson GC, Hurst JR, Seemungal TAR, Wedzicha JA. Early therapy improves outcomes of exacerbations of chronic obstructive pulmonary disease. Am J Resp Crit Care Med 2004;169:1298-393. doi:10.1164/ rccm.200310-14430C

20. Fletcher CM (Chairman). Standardised questionnaire on respiratory symptoms: a statement prepared and approved by the MRC Committee on the Aetiology of Chronic Bronchitis (MRC breathlessness score). BMJ 1960;2:1665.

21. Ritchie J and Lewis J (eds) (2004) Qualitative Research Practice. A Guide for Social Science Students. Sage Publications: London.

22. NVivo 7 (QSR International Ltd, Victoria, Australia).

23. Ostrowski S, Grzywa-Celinska A, Mieczkowska J, et al. Pulmonary function between 40 and 80 years of age. J Physiol Pharm 2005;56Suppl 4:127-33.

24. Garcia-Rio F, Pino JM, Dorgham A, Alonso A, Villamor J. Spirometric reference equations for European females and males aged 65-85 yrs. Eur Resp $J$ 2004;24(3):397-405. doi:10.1183/09031936.04.00088403

25. Curtis, JR, Engelberg RA, Nielson EL, Au DH, Patrick DL. Patient-physician communication about end-of-life care for patients with severe COPD. Eur Resp J 2004;24:200-05. doi:10.1183/09031936.04.00010104

26. Gulliford MC, Naithani S, and Morgan S. Continuity of care and intermediate outcomes of type 2 diabetes mellitus. Family Practice 2007;24:245-51. doi:10.1093/fampra/cmm014

27. Baker R, Boulton M, Windridge K, Tarrant C, Bankart J, Freeman GK. Interpersonal continuity of care: A cross sectional survey of primary care patients preferences and their experience. Br J Gen Pract 2007;57:283-9.

28. Thomas K. Caring for the Dying at Home (2003) Radcliffe. 